\title{
NHậN XÉT MỘT SỐ ĐặC ĐIỂM KỸ THUẬT TRONG PHẪU THUẬT NỘI SOI ĐIỀU TR! TRÀN KHÍ MÀNG PHỔI TỬ PHÁT NGUYÊN PHÁT TẠI BỆNH VIỆN QUÂN Y 103
}

\author{
Nguyê̂n Ngoc Trung*, Nguyễn Trưòng Giang*, Nguyến Văn Nam*
}

\section{TÓM TẮT}

Mục tiêu: Nhận xét một số đặc điểm kỹ thuật trong phẫu thuật nội soi điều trị tràn khí màng phổi tự phát nguyên phát tại Bệnh viện Quân Y 103.

Đối tượng và phương pháp nghiên cứu: nghiên cứu mô tả cắt ngang, kết hợp hồi cứu và tiến cứu 33 bệnh nhân chẩn đoán tràn khí màng phổi tự phát nguyên phát được điều trị bằng phương pháp phẫu thuật nội soi tại khoa Phẫu thuật Lồng ngực - Tim mạch, Bệnh viện Quân Y 103 từ tháng 01/2013 đến tháng 6/2015.

Kết quả: Nam 31 trường hợp $(93,9 \%), 2$ trường hợp nữ $(6,1 \%)$. Tuổi trung bình $30,15 \pm 2,065$ tuổi (thấp nhất 15 , cao nhất 58 tuổi). Tràn khí màng phổi mức độ nhẹ chiếm $9,1 \%$, chủ yếu là tràn khí mức độ vừa $(39,4 \%)$ và mức độ nặng $(51,5 \%)$. Phương pháp xử trí bóng khí kẹp bằng clip có khóa $(54,6 \%), 9,1 \%$ khâu bóng khí. Phương pháp gây dính màng phổi chủ yếu là làm xước màng phổi thành vùng đỉnh kết hợp với povidone $10 \%(57,6 \%), 12$ bệnh nhân $(36,4 \%)$ gây dính bằng povidone, 2 bệnh nhân (6\%) không gây dính màng phổi. Thời gian phẫu thuật trung bình $60,12 \pm 3,17$ phút. Biến chứng sau mổ: rò khí kéo dài 4 bệnh nhân (12,1 \%), không có biến chứng chảy máu hay nhiễm trùng.

Kết luận: Nội soi lồng ngực là phương pháp an toàn, hiệu quả trong điều trị tràn khí màng phổi tự phát nguyên phát lần đầu. Phẫu thuật có tỉ lệ tái phát thấp, khả năng hồi phục nhanh, thời gian điều trị ngắn.

*Tù khóa: tràn khí màng phổi tự phát nguyên phát, phẫu thuật nội soi lồng ngực.
REVIEWS SOME SPECIFICATION IN

THORACOSCOPY OF TREATMENT OF

PRIMARY SPONTANEOUS PNEUMOTHORAX AT 103 MILITARY HOSPITAL

\section{SUMMARY}

Objective: Reviews some specification of thoracoscopy treatment of spontaneous pneumothorax primary at 103 Military Hospital.

Objects and method: retrospective and prospective study of 33 patients diagnosed primary spontaneous pneumothorax were treated by thoracoscopy at cardiothoracic department of 103 Military Hospital from 1/2013 to 6/2015.

Results: Men 31 cases (93.9\%), 2 women (6.1\%). The average age $30.15 \pm 2.065$ years $(15-58)$. Method of bullaes with locking clip (54.6\%), 9.1\% suture. Methods to create a pleural symphysis were brushing the pleura combined pleurodesis by iodopovidone (57.6\%), 12 patients $(36.4 \%)$ were pleurodesis by iodopovidone, 2 patients $(6 \%)$ without pleurodesis. The average surgical time $60.12 \pm 3.17$ minutes. Postoperative complications: 4 patients were air leak (12.1\%), no bleeding and infections complications. ${ }^{*}$

Conclusions: Thoracoscopy is safe and effective in the treatment of primary spontaneous pneumothorax with a low recurrence rates, faster recovery, shorter treatment time.

*Key words: primary spontaneous pneumothorax, thoracoscopy.

\footnotetext{
* Bệnh viện Quân Y 103

Người chịu trách nhiệm khoa họ:

- Ngày nhận bài: 10/01/2016

PGS.TS. Nguyễn Truòng Giang

- Ngày Cho Phép Đăng: 24/02/2016

Phản Biện Khoa họ: PGS.TS. Đặng Ngọc Hùng

GS.TS. Lê Ngọc Thành
} 


\section{1. ĐẶT VẤN ĐỀ}

Tràn khí màng phổi là tình trạng khí tích tụ trong khoang màng phổi. Tràn khí màng phổi tự phát nguyên phát (Primary spontaneous pneumothorax) (TKMPTPNP) được định nghĩa là tràn khí màng phổi tự phát mà không có bệnh lý phổi trước đó. Tràn khí màng phổi tự phát nguyên phát thường nguyên nhân do vỡ các bóng khí ở màng phổi tạng hay các kén khí. Tỷ lệ tràn khí màng phổi tự phát nguyên phát là 7,4 - $18 / 100.000$ dân/năm ở nam giới và 1,2 - 6/100. 000 dân/năm ở phụ nữ. Bệnh thường gặp ở nam giới có thể trạng cao, gày, tuổi hay gặp từ 10 - 30 tuổi.[1], [2], [3].

Điều trị phẫu thuật đối với tràn khí màng phổi tự phát nguyên phát mục tiêu là cắt bỏ các bóng khí hoặc khâu các lỗ rò khí ở vùng đỉnh phổi để điều trị các nguy cơ tiềm ẩn, mục tiêu thứ hai là tạo ra một màng dính ở màng phổi để ngăn ngừa tái phát. Ngày nay với sự phát triển của phẫu thuật nội soi lồng ngực cùng với những ưu điểm như xâm lấn ít, khả năng kiểm soát tổn thương tốt hơn, phục hồi sau mổ nhanh hơn, phẫu thuật nội soi ngày càng được ứng dụng rộng rãi hơn trong điều trị tràn khí màng phổi tự phát nguyên phát.[2], [3].

Tuy nhiên, vẫn còn tồn tại nhiều tranh cãi trong việc lựa chọn kỹ thuật phẫu thuật tối ưu để phát hiện và xử lý các bóng khí, kỹ thuật gây dính màng phổi với hiệu quả tốt và ít tác dụng phụ nhằm cải thiện tốt hơn kết quả điều trị tràn khí màng phổi tự phát nguyên phát.

Xuất phát từ những yêu cầu thực tế nói trên chúng tôi thực hiện đề tài nhằm mục tiêu: Nhận xét một số đặc điểm kỹ thuật trong phẫu thuật nội soi điều trị tràn khi màng phổi tư phát nguyên phát tại Bệnh viện Quân Y 103.

\section{2. ĐỐI TƯợNG VÀ PHƯƠNG PHÁP NGHIÊN CÚU}

\section{1. Đối tượng nghiên cứu:}

Gồm 33 bệnh nhân chẩn đoán tràn khí màng phổi tự phát nguyên phát được điều trị bằng phương pháp phẫu thuật nội soi tại khoa Phẫu thuật Lồng ngực Tim mạch, Bệnh viện Quân Y 103 từ tháng 01/2013 đến tháng 6/2015.

\section{- Tiêu chuẩn lựa chọn.}

Những bệnh nhân được chẩn đoán tràn khí màng phổi tự phát nguyên phát và được phẫu thuật nội soi.

- Tiêu chuẩn loại trừ

+ Bệnh nhân có tràn khí màng phổi do vết thương hoặc chấn thương ngực.

+ Tràn khí khoang màng phổi do tai biến thở máy với áp lực cao, thủ thuật chọc tĩnh mạch dưới đòn, mở khí quản...

+ Những bệnh nhân không đồng ý tham gia nghiên cứu.

\subsection{Phương pháp nghiên cứu:}

- Thiết kế nghiên cứu:

Nghiên cứu mô tả cắt ngang, kết hợp hồi cứu và tiến cứu.

- Các chỉ tiêu nghiên cứu

+ Lâm sàng: tuổi, giới tính, tiền sử, triệu chứng cơ năng

+ Cận lâm sàng: Chụp $X$ quang lồng ngực chuẩn.

\section{+Chỉ tiêu phẫu thuật:}

\section{- Qui trình phẫu thuật}

+ Chuẩn bị bệnh nhân: Bệnh nhân được chẩn đoán xác định tràn khí màng phổi và làm đầy đủ các xét nghiệm về chức năng gan, thận, xét nghiệm đông máu.

+ Vô cảm: bằng ống nội khí quản 2 nòng

+ Tư thế bệnh nhân: tư thế nghiêng $90^{\circ}$ về phía bên đối diện.

+ Các bước phẫu thuật

- Bước 1: Xác định vị trí và số lượng đặt trocar.

- Bước 2: Quan sát, đánh giá tổn thương.

- Bước 3: Xử trí bóng khí.

- Bước 4: Làm dính màng phổi chống tái phát.

- Bước 5: Kết thúc phẫu thuật. Cho phổi nở, kiểm tra rò khí. Đặt ống dẫn lưu kích cỡ $28 \mathrm{~F}$ qua chỗ đặt trocar ở đường nách giữa, đầu ống được đưa lên sát trên đỉnh. Ống hút được nối ngay với hệ thống dẫn lưu kín.

\subsection{Xử lý số liệu:}

Các bệnh nhân nghiên cứu được nhập và quản lý số liệu theo mẫu bệnh án thống nhất. Xử lý kết quả bằng phần mềm $\mathrm{EPI}$ - INFO và Epicalc. 


\section{KẾT QUẢ NGHIÊN CÚU}

Bảng 1: Đặc điểm chung

\begin{tabular}{|c|c|c|c|}
\hline \multicolumn{2}{|c|}{ Thông số nghiên cứu } & $\begin{array}{c}\text { Số bệnh } \\
\text { nhân }\end{array}$ & $\begin{array}{c}\text { Giá trị trung } \\
\text { bình và tỉ lệ \%o }\end{array}$ \\
\hline \multicolumn{2}{|c|}{ Tuối trung bình (năm) } & 33 & $30,15 \pm 2,065$ \\
\hline \multirow{2}{*}{ Giới tính } & Nam & 31 & 93,9 \\
\cline { 2 - 4 } & Nữ & 2 & 6,1 \\
\hline
\end{tabular}

Đa số bệnh nhân là nam 31 trường hợp chiếm $93,9 \%$ và 2 trường hợp nữ chiếm $6,1 \%$. Tuổi thấp nhất là 15 , cao nhất là 58 tuổi. Trung bình $30,15 \pm 2,065$ tuổi, bệnh lý xảy ra chủ yếu ở lứa tuổi lao động.

Bảng 2: Mức độ tràn khí trên phim chụp X quang lồng ngục

\begin{tabular}{|c|c|c|}
\hline Mức độ tràn khí & Số bệnh nhân & Tỉ lệ \% \\
\hline Nhẹ & $3 / 33$ & 9,1 \\
\hline Vừa & $13 / 33$ & 39,4 \\
\hline Nặng & $17 / 33$ & 51,5 \\
\hline Tổng & $33 / 33$ & 100 \\
\hline
\end{tabular}

Tràn khí màng phổi mức độ nhẹ chiếm 9,1\%, chủ yếu là tràn khí mức độ vừa $(39,4 \%)$ và mức độ nặng $(51,5 \%)$.

Bảng 3: Vị trí bên màng phổi bị tràn khí

\begin{tabular}{|l|c|c|}
\hline $\begin{array}{c}\text { Vị trí bên màng phổi bị } \\
\text { tràn khí }\end{array}$ & $\begin{array}{c}\text { Số bệnh } \\
\text { nhân }\end{array}$ & Tỉ lệ \% \\
\hline Phổi phải & $12 / 33$ & 36,4 \\
\hline Phổi trái & $21 / 33$ & 63,6 \\
\hline Cả hai phổi & $0 / 33$ & 0 \\
\hline Tổng & $33 / 33$ & 100 \\
\hline
\end{tabular}

Vị trí tràn khí màng phổi bên phải chiếm $36,4 \%$, bên trái là $63,4 \%$.

Bảng 4: Số lượng lỗ trocar đặt trong mổ

\begin{tabular}{|l|c|c|}
\hline \multicolumn{1}{|c|}{ Số lượng lỗ trocar } & $\begin{array}{c}\text { Số bệnh } \\
\text { nhân }\end{array}$ & Tỉ lệ \\
\hline Đặt 3 trocar & 21 & $63,6 \%$ \\
\hline Đặt 2 trocar & 12 & $36,4 \%$ \\
\hline Tổng số & 33 & $100 \%$ \\
\hline
\end{tabular}

21 bệnh nhân trong mổ được đặt 3 trocar $(63,6 \%)$, có 12 trường hợp $(36,4 \%)$ đặt 2 trocar.
Bảng 5: Tổn thương trong mổ và cách xử trí

\begin{tabular}{|c|c|c|c|c|}
\hline $\begin{array}{c}\text { Phân } \\
\text { loại }\end{array}$ & $\begin{array}{c}\text { Tổn } \\
\text { thương }\end{array}$ & $\begin{array}{c}\text { Số } \\
\text { ca }\end{array}$ & $\begin{array}{c}\text { Tỉ lệ } \\
\mathbf{\%}\end{array}$ & Xử trí \\
\hline Nhóm 1 & $\begin{array}{c}\text { Phối bình } \\
\text { thường }\end{array}$ & 12 & 36,4 & Làm dính \\
\hline Nhóm 2 & $\begin{array}{c}\text { Bóng khí } \\
\text { vờ dính } \\
\text { màng phổi }\end{array}$ & 3 & 9,1 & $\begin{array}{c}\text { Gỡ dình, kẹp tổn } \\
\text { thương bắng clip có } \\
\text { khóa +làm dính }\end{array}$ \\
\hline Nhóm 3 & $\begin{array}{c}\text { Bóng khí } \\
<2 \mathrm{~cm}\end{array}$ & 15 & 45,5 & $\begin{array}{c}\text { Kẹp bóng khí bằng } \\
\text { clip có khóa + làm } \\
\text { dính }\end{array}$ \\
\hline Nhóm 4 & $\begin{array}{c}\text { Bóng khí } \\
>2 \mathrm{~cm}\end{array}$ & 3 & 9,1 & $\begin{array}{c}\text { Khâu bóng khí }+ \\
\text { làm dính }\end{array}$ \\
\hline Tổng & & 33 & 100 & \\
\hline
\end{tabular}

Có 12/33 bệnh nhân $(36,4 \%)$ không phát hiện tổn thương trong mổ, 63,5\% phát hiện bóng khí ở phổi ( $9,1 \%$ bóng khí đã vỡ dính vào màng phổi). Hầu hết phương pháp xử trí với bóng khí là kẹp bằng clip có khóa $(54,6 \%)$, có 9,1\% khâu bóng khí.

\section{Bảng 6. Phương pháp gây dính màng phổi}

\begin{tabular}{|l|c|c|}
\hline \multicolumn{1}{|c|}{$\begin{array}{c}\text { Phương pháp gây dính } \\
\text { màng phồi }\end{array}$} & $\begin{array}{c}\text { Số bệnh } \\
\text { nhân }\end{array}$ & Tỉ lệ \% \\
\hline Gây dính bằng povidone $10 \%$. & 12 & $36,4 \%$ \\
\hline $\begin{array}{l}\text { Làm xước lá thành màng phổi } \\
\text { + povidone } 10 \%\end{array}$ & 19 & $57,6 \%$ \\
\hline Không gây dính & 2 & $6 \%$ \\
\hline Tổng số & 33 & $100 \%$ \\
\hline
\end{tabular}

Phương pháp gây dính màng phổi chủ yếu là làm xước màng phổi thành vùng đỉnh kết hợp với povidone $10 \%(57,6 \%)$, có 12 bệnh nhân $(36,4 \%)$ chỉ gây dính bằng povidone, có 2 bệnh nhân $(6 \%)$ không gây dính màng phổi.

Bảng 7. Thòi gian phẫu thuật và thòi gian nằm viện

\begin{tabular}{|l|c|c|c|}
\hline \multicolumn{1}{|c|}{$\begin{array}{c}\text { Thông số nghiên } \\
\text { cứu }\end{array}$} & $\begin{array}{c}\text { Ngắn } \\
\text { nhất }\end{array}$ & $\begin{array}{c}\text { Dài } \\
\text { nhất }\end{array}$ & $\begin{array}{c}\text { Trung } \\
\text { bình }\end{array}$ \\
\hline $\begin{array}{l}\text { Thời gian phẫu thuật } \\
\text { (phút) }\end{array}$ & 30 & 90 & $\begin{array}{c}60,12 \\
\pm 3,177\end{array}$ \\
\hline $\begin{array}{l}\text { Thời gian nằm viện } \\
\text { sau mổ (ngày) }\end{array}$ & 3 & 19 & $6,76 \pm 0,605$ \\
\hline $\begin{array}{l}\text { Thời gian nằm viện } \\
\text { (ngày) }\end{array}$ & 5 & 22 & $11 \pm 0,76$ \\
\hline
\end{tabular}


Thời gian phẫu thuật $60,12 \pm 3,177$ phút, thời gian sau mổ $6,76 \pm 0,605$ ngày, Thời gian nằm viện $11 \pm 0,76$ ngày.

Bảng 8. Biến chứng sớm sau mổ

\begin{tabular}{|l|c|c|}
\hline \multicolumn{1}{|c|}{ Biến chứng sau mổ } & $\begin{array}{c}\text { Số bệnh } \\
\text { nhân }\end{array}$ & $\begin{array}{c}\text { Tỉ lệ } \\
\mathbf{( \% )}\end{array}$ \\
\hline Rò khí kéo dài & $4 / 33$ & 12,1 \\
\hline Tràn máu màng phối & $0 / 33$ & 0 \\
\hline Máu đông màng phổi & $0 / 33$ & 0 \\
\hline Viêm mủ màng phổi & $0 / 33$ & 0 \\
\hline Viêm phổi & $0 / 33$ & 0 \\
\hline
\end{tabular}

Biến chứng: rò khí kéo dài 4 trường hợp chiếm $12,1 \%$, không có biến chứng tràn máu màng phổi, máu đông màng phổi, nhiễm trùng hay viêm phổi.

\section{BÀN LUẬN}

\section{1. Đặc điểm chung:}

- Kết quả nghiên cứu của chúng tôi thấy đa số bệnh nhân là nam có 31 trường hợp chiếm $93,9 \%$ và 2 trường hợp nữ chiếm $6,1 \%$. Tuổi trung bình là 30,15 $\pm 2,065$ tuổi (thấp nhất 15 , cao nhất 58 tuổi).

Kết quả nghiên cứu cũng tương tự như một số nghiên cứu như của Chiu C.Y nghiên cứu trên 171 bệnh nhân tràn khí màng phổi tự phát nguyên phát thấy tỉ lệ nam/nữ là $9 / 1$. Tuy nhiên nghiên cứu của tác giả tuổi trung bình lại khá thấp là 17,6 $\pm 1,5$ tuổi.[5]

- Hình ảnh $\mathrm{X}$ quang lồng ngực:

Mức độ tràn khí cũng là gợi ý cho chỉ định can thiệp và tiên lượng kết quả sau phẫu thuật. Nghiên cứu của Young Choi $\mathrm{S}$ nhận thấy với các bệnh nhân tràn khí màng phổi nặng hay các thương tổn như bóng khí phát hiện thấy trên phim chụp $\mathrm{X}$ quang ngực có liên rõ rệt đến tỉ lệ tái phát hay rò khí kéo dài.[8].

Trong nghiên cứu của chúng tôi nhận thấy tràn khí màng phổi mức độ nhẹ chiếm $9,1 \%$, chủ yếu là tràn khí mức độ vừa $(39,4 \%)$ và mức độ nặng $(51,5 \%)$. Vị trí tràn khí màng phổi bên phải chiếm $36,4 \%$, bên trái là $63,4 \%$. Như vậy hầu hết các bệnh nhân đều tràn khí mức độ vừa và nặng, tuy vị trí tràn khí bên trái nhiều hơn nhưng số bệnh nhân bị tràn khí bên trái cũng không có biểu hiện về thay đổi huyết động so với tràn khí bên phải. Trong nghiên cứu của chúng tôi cũng nhận thấy tất cả các bệnh nhân đều không có tràn máu màng phổi từ vừa đến nặng kèm theo, một số bệnh nhân trong khi nội soi kiểm tra chỉ có ít dịch tiết màu hồng nhạt trong khoang màng phổi.

\section{2. Đặc điểm kỹ thuật phẫu thuật:}

- Vị trí đặt trocar:

Về vị trí các đường để đặt trocar các tác giả đều thống nhất theo nguyên tắc hình "kim cương", để đảm bảo thuận lợi trong quá trình thao tác các dụng cụ phẫu thuật. Theo nghiên cứu của Ambrogi M.C và cs sử dụng 3 trocar: 1 trocar $10 \mathrm{~mm}$ ở khoang liên sườn VIII đường nách giữa, 1 trocar $12 \mathrm{~mm}$ ở khoang liên sườn $\mathrm{V}$ đường nách trước dùng để đưa stapler và 1 trocar $12 \mathrm{~mm}$ ở liên sườn $\mathrm{V}$ đường nách sau lệch ra vị trí của mỏm xương bả vai cũng để thao tác dụng cụ stapler nếu cần thiết.[4]

Tác giả Parrish $\mathrm{S}$ và cs cũng đặt 3 trocar, vị trí của mỗi trocar lại thay đổi, 1 trocar ở khoang liên sườn $\mathrm{V}$ đường nách giữa để đưa camera và 2 trocar khác ở vị trí liên sườn VI đường nách trước và liên sườn IV đường nách sau để đưa dụng cụ.[5]

Nghiên cứu của chúng tôi có 21 bệnh nhân trong mổ được đặt 3 trocar $(63,6 \%)$, có 12 trường hợp $(36,4 \%)$ đặt 2 trocar. Về vị trí đặt trocar chúng tôi cũng đặt 1 trocar $10 \mathrm{~mm}$ qua liên sườn VII đường nách giữa, vị rí này dùng để đưa camera đánh giá tổn thương, một trocar qua liên sườn $\mathrm{V}$ đường nách trước. Qua 2 trocar này vén phổi để kiểm tra tổn thương. Nếu tổn thương chỉ là các bóng khí nhỏ có thể kẹp ngay được thì chỉ cần sử dụng 2 lỗ trocar, và sau đó gây xước lá thành màng phổi vùng đỉnh để gây dính. Nếu tổn thương phức tạp hơn chúng tôi sẽ sử dụng thêm một lỗ trocar nữa qua liên sườn $\mathrm{V}$ đường nách sau để đưa thêm dụng cụ vào xử trí tổn thương cụ thể, trocar thứ 3 này chúng tôi thường sử dụng trocar $5 \mathrm{~mm}$ để giảm thiểu sang chấn.

- Tổn thương trong phẫu thuật và xử trí:

Nghiên cứu của chúng tôi nhận thấy có $12 / 33$ bệnh nhân $(36,4 \%)$ không phát hiện tổn thương trong mổ, Có $63,5 \%$ số bệnh nhân phát hiện bóng khí ở phổi trong đó $9,1 \%$ bóng khí đã vỡ dính vào khoang màng phổi.

Hầu hết phương pháp xử trí với bóng khí là kẹp bằng clip có khóa $(54,6 \%)$, có $9,1 \%$ khâu bóng khí. Tất cả các bệnh nhân đều được gây dính màng phổi 
bằng đốt lá thành và bơm povidone $10 \%$ vào khoang màng phổi.

Tổn thương kiểm tra thấy trong mổ rất quan trọng, quyết định phương pháp can thiệp vào khoang màng phổi và vào phổi tiếp theo, tiên lượng được khả năng tái phát hay rò khí kép dài sau mổ. Trường hợp không nhìn thấy tổn thương thì chỉ cần làm xước màng phổi thành và bơm dung dịch povidone $10 \%$ kích thích tạo dính để tránh tái phát. Nếu thấy dày dính khoang màng phổi thì nên gỡ dính để phổi nở tốt, đồng thời làm xước màng phổi với mục đính như trên.

Một số tác giả đề nghị nếu không thấy bóng khí hay chỉ có dính màng phổi vẫn cắt hình chêm vùng phổi nơi có tổn thương để ngăn ngừa tái phát, kèm theo chà xước màng phổi tạo dính để giảm tỉ lệ tái phát.

Nếu có những bóng khí nhỏ $(<2 \mathrm{~cm})$ có thể cắt bóng khí bằng thòng lọng kết hợp khâu tăng cường hay stapler cắt bóng khí. Chúng tôi thực hiện kẹp bóng khí bằng clip có khóa qua phẫu thuật nội soi, phương pháp hiệu quả và qua theo dõi hầu như không có tái phát hay rò khí kéo dài với các bệnh nhân này.

Đối với bóng khí lớn hơn $2 \mathrm{~cm}$ hay nhiều bóng khí chúng tôi tiến hành khâu bóng khí qua nội soi thay cho kẹp bằng stapler, theo chúng tôi biện pháp này cũng đem lại hiệu quả, giảm chi phí phẫu thuật.

- Phương pháp gây dính màng phổi:

Mục đích gây dính màng phổi trong phẫu thuật tràn khí màng phổi tự phát nguyên phát là để ngăn ngừa tái phát. Có nhiều nghiên cứu của các tác giả trên thế giới và trong nước về các phương pháp gây dính và kết quả của từng phương pháp.

Theo nghiên cứu của How C.H nhận thấy trên 1083 bệnh nhân phẫu thuật nội soi lồng ngực được gây dính màng phổi bằng hóa chất cả trong mổ hay trên các trường hợp còn rò khí sau mổ đều cho tỉ lệ tái phát và rò khí kéo dài sau mổ thấp.[6]

Theo khuyến cáo của hội phẫu thuật lồng ngực Mỹ và hội Lồng ngực của Anh, hiện nay không nên sử dụng gây dính màng phổi bằng hóa chất mà chỉ nên sử dụng phương pháp gây dính màng phổi bằng biện pháp cơ học để điều trị chống tái phát đối với tràn khí màng phổi tự phát nguyên phát.
Trong nghiên cứu của chúng tôi, sử dụng phương pháp gây dính màng phổi chủ yếu là làm xước màng phổi thành vùng đỉnh kết hợp với povidone $10 \%$ có 19 bệnh nhân $(57,6 \%)$, có 12 bệnh nhân $(36,4 \%)$ chỉ gây dính bằng povidone, có 2 bệnh nhân $(6 \%)$ không gây dính màng phổi. Chủ yếu chúng tôi chọn làm dính bằng làm xước cơ học màng phổi thành kết hợp với povidone $10 \%$. Theo chúng tôi nhận thấy kỹ thuật này dễ thực hiện, chi phí thấp đạt hiệu quả cao và ít biến chứng. Tuy nhiên chúng tôi nhận thấy một số bệnh nhân gây dính bằng povidone sau mổ thường có phản ứng sốt từ vừa đến cao khoảng $1-2$ ngày. Điều này cần nghiên cứu và theo dõi đánh giá thêm. Có 2 bệnh nhân sau khi kiểm tra thấy không có tổn thương rõ ràng ở phổi chúng tôi chỉ kẹp bằng clip có khóa ở vị trí nghi ngờ ở vùng đỉnh phổi sau đó quyết định không gây dính màng phổi.

\subsection{Kết quả phẫu thuật:}

- Thời gian phẫu thuật:

Nghiên cứu của chúng tôi thấy: thời gian phẫu thuật $60,12 \pm 3,177$ phút, thời gian sau mổ $6,76 \pm 0,605$ ngày, Thời gian nằm viện $11 \pm 0,76$ ngày. Về biến chứng phẫu thuật có 4 trường hợp rò khí kéo dài chiếm $12,1 \%$, không có biến chứng tràn máu màng phổi, máu đông màng phổi, nhiễm trùng hay viêm phổi.

Về số ngày nằm điều trị sau mổ trong nghiên cứu của chúng tôi dài hơn so với các nghiên cứu khác, một phần do điều kiện hậu phẫu tại cơ sở điều trị, một phần do có thể thời gian để dẫn lưu màng phổi dài hơn, tuy nhiên theo chúng tôi thời gian này so với các nghiên cứu khác là không quá dài và chấp nhận được.

- Biến chứng sớm sau mổ:

Biến chứng sớm sau phẫu thuật nội soi điều trị tràn khí màng phổi tự phát bao gồm: rò khí kéo dài, chảy máu, nhiễm trùng (phổi, màng phổi, thành ngực). Chủ yếu nguy cơ các biến chứng xảy ra có liên quan đến phương pháp xử trí trên phổi và phương pháp gây dính khoang màng phổi.

Biến chứng hay gặp và cũng là điều các nghiên cứu quan tâm nhiều nhất là rò khí kéo dài. Cũng có nhiều nghiên cứu khác đề cập đến tỉ lệ rò khí nhiều hơn ở nhóm bệnh nhân chỉ gây dính bằng phương pháp làm xước lá thành. Tuy vậy một số tác giả lại 
cho rằng nguy cơ rò khí sau mổ liên quan chủ yếu đến việc kiểm tra và xử trí tổn thương các bóng khí ở phổi trong khi phẫu thuật. theo các tác giả này chủ yếu rò khí là do bỏ sót tổn thương các bóng khí trong mổ, ở đây phần lớn là do các bóng khí nằm ở các vị trí khó kiểm tra như nằm ở dưới lá tạng màng phổi nên không quan sát thấy được trong khi phẫu thuật.

Trong nghiên cứu của chúng tôi có 4 trường hợp rò khí kéo dài, các bệnh nhân này thường có nhiều bóng khí nhỏ rãi rác, quá trình phẫu thuật không cắt được toàn bộ, sau mổ các bóng khí nhỏ còn sót có thể vỡ ra gây rò khí. Trong 4 trường hợp rò khí sau mổ, có 1 trường hợp phải mở ngực nhỏ để xử lý tổn thương khâu lại chỗ rò, 1 trường hợp phải đặt dẫn lưu khoang màng phổi còn lại 2 trường hợp theo dõi hút dẫn lưu thêm, bệnh ổn định, hết rò khí. Ngoài ra không có biến chứng khác.

\section{KẾT LUẬN}

5.1. Đặc điểm lâm sàng và $X$ quang tràn khí màng phổi tự phát, nguyên phát:

- Đa số bệnh nhân là nam 31 trường hợp $(93,9 \%)$ và 2 trường hợp nữ $(6,1 \%)$.

- Tuổi trung bình 30,15 $\pm 2,065$ tuổi (thấp nhất 15 , cao nhất 58 tuổi). Bệnh gặp chủ yếu ở lứa tuổi lao động (nhóm tuổi 20 - 40 tuổi chiếm 57,6\%).

- Trên phim X quang: tràn khí màng phổi mức độ nhẹ chiếm $9,1 \%$, chủ yếu là tràn khí mức độ vừa $(39,4 \%)$ và mức độ nặng $(51,5 \%)$.

\subsection{Một số đặc điểm kỹ thuật và kết quả phẫu thuật nội soi điều trị tràn khí màng phổi tự phát nguyên phát:}

- Phương pháp xử trí bóng khí: hầu hết phương pháp xử trí với bóng khí là kẹp bằng clip có khóa (54,6\%), có 9,1\% khâu bóng khí.

- Phương pháp gây dính màng phổi chủ yếu là làm xước màng phổi thành vùng đỉnh kết hợp với povidone $10 \%(57,6 \%), 12$ bệnh nhân $(36,4 \%)$ chỉ gây dính bằng povidone, 2 bệnh nhân $(6 \%)$ không gây dính màng phổi.

- Thời gian phẫu thuật $60,12 \pm 3,177$ phút, thời gian nằm viện sau mổ $6,76 \pm 0,605$ ngày, Thời gian nằm viện $11 \pm 0,76$ ngày. Biến chứng: rò khí kéo dài 4 trường hợp chiếm $12,1 \%$, không có biến chứng chảy máu hay nhiễm trùng.

\section{TÀI LIỆ THAM KHẢO}

1. Đặng Ngọc Hùng (1992), "Tràn khí màng phổi tự phát", Bệnh học ngoại khoa, (1), Học viện quân y, tr. 412- 417.

2. Hoàng Thị Quế, và cộng sự (2003), "Biến chứng của điều trị phòng ngừa tái phát tràn khí màng phổi tự phát bằng bơm talc nhũ tương qua ống dẫn lưu màng phổi", Tạp chí Y học TP Hồ Chí Minh, Tập VII, Tr 96 - 101.

3. Nguyễn Thế Vũ (2003), "Nghiên cứu đặc điểm lâm sàng, Xquang và chỉ định điều trị tràn khí màng phổi tự phát", luận văn thạc sỹ Y khoa, Đại học Y Hà Nội.

4. Ambrogi MC, Zirafa CC, Davini F, Giarratana S, Lucchi M, Fanucchi O, Melfi F, Mussi A. (2015), Transcollation ${ }^{\circledR}$ technique in the thoracoscopic treatment of primary spontaneous pneumothorax. Interact Cardiovasc Thorac Surg. Apr;20(4):4458.

5. Chiu CY, Chen TP, Wang CJ, Tsai MH, Wong KS. (2014), Factors associated with proceeding to surgical intervention and recurrence of primary spontaneous pneumothorax in adolescent patients. Eur J Pediatr. Nov;173(11):1483-90.

6. How CH, Tsai TM, Kuo SW, Huang PM, Hsu HH, Lee JM, Chen JS, Lai HS. (2014), Chemical pleurodesis for prolonged postoperative air leak in primary spontaneous pneumothorax. J Formos Med Assoc. May;113(5):284-90.

7. Parrish S, Browning RF, Turner JF Jr, Zarogoulidis K, Kougioumtzi I, Dryllis G, Kioumis I, Pitsiou G, Machairiotis N, Katsikogiannis N, Tsiouda $\mathrm{T}$, Madesis A, Karaiskos T, Zarogoulidis P. (2014), The role for medical thoracoscopy in pneumothorax. J Thorac Dis. Oct; 6(Suppl 4):S383-91.

8. Young Choi $\mathrm{S}^{1}$, Beom Park C, Wha Song S, Hwan Kim Y, Cheol Jeong S, Soo Kim K, Hyon Jo K. (2014), What factors predict recurrence after an initial episode of primary spontaneous pneumothorax in children? Ann Thorac Cardiovasc Surg. 2014;20(6):961-7 